\title{
Enhancing the Visualization of Law
}

\author{
Michael Curtotti \\ Research School of Computer Science \\ Australian National University \\ michael.curtotti@anu.edu.au
}

\author{
Eric McCreath
}

Research School of Computer Science

Australian National University

eric.mcreath@anu.edu.au *

October 2, 2012

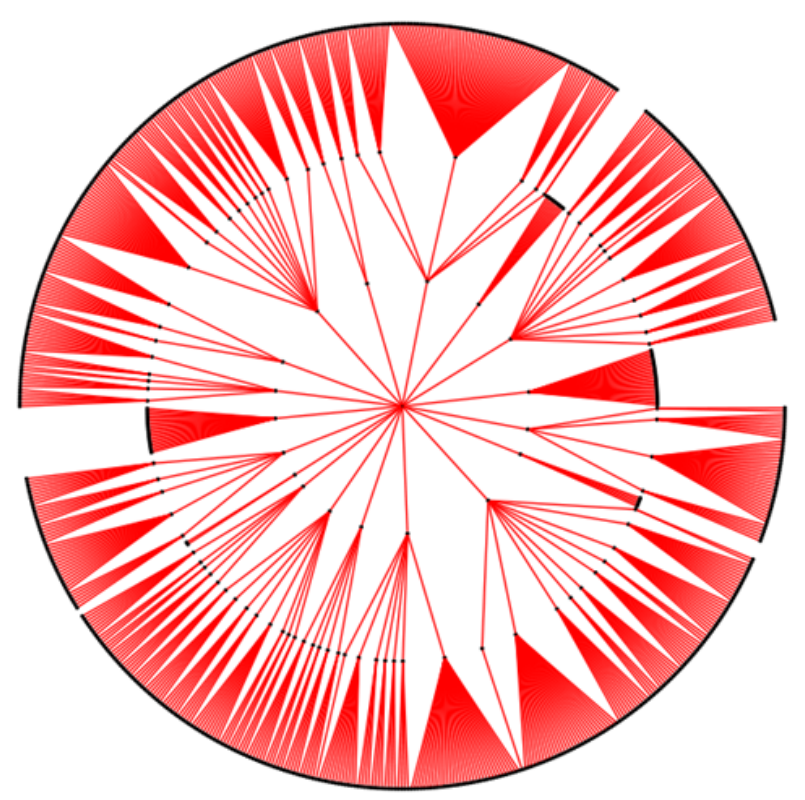

Figure 1: The formal structure of the Copyright Act 1968 (Aust)

\section{Contents}

1 Introduction

2 A Survey of Online Visualization of Legislation 3

2.1 Before the Information Age . . . . . . . . . . . . . . . . . . . 3

2.2 Public good publication online . . . . . . . . . . . . 6

2.3 Official sites . . . . . . . . . . . . . . . . . . . . 8

2.3.1 Selected Australian Jurisdictions . . . . . . . . . . . . . 8

${ }^{*}$ Acknowledgements: We gratefully acknowledge the kind assistance of Helena Haapio http://lexpert.com, Peter Spooner and the anonymous reviewers who provided feedback on an earlier draft of this paper. 
2.3.2 Selected U.S. Jurisdictions . . . . . . . . . . . . . . . . . 10

2.3.3 The United Kingdom . . . . . . . . . . . . . . . . . . . . . . . . . 11

2.4 Legislative Data and Hacker Visualizations of Law . . . . . . . . . . . . . . 12

2.5 Novel and Purpose Specific Visualizations . . . . . . . . . . . . . 14

3 Visualizing Definition Networks 16

4 Towards a Theory of Legislative Visualization? 18

4.1 Visualization Theory . . . . . . . . . . . . . . . . . . . 18

4.2 Suggestions for Framing Legislative Visualization . . . . . . . . . . . . 19

4.3 Evaluating Legislative Visualizations . . . . . . . . . . . . . . 20

5 Conclusions 23

References 24

\section{Introduction}

The accessibility of law has undergone a revolution in the last two decades as public good, official and commercial initiatives have made legislation (and other legal materials) accessible onlinet. In respect of legislation, this development has followed centuries of refinement in how the law is written and presented. The presentation of the law (or in its 21st century manifestation - its visualization) has long been known to influence its readability (itself a dimension of the accessibility of law).

Online legislation sites vary widely in their approaches. The most basic present legislation as a scrollable text (in practice reverting to the equivalent of a single scroll of paper), the most novel use features such as colour, graphs, images, moving pictures and information enhancement to improve visualizations. Some sites focus on providing laws as downloadable documents in various formats - emphasising the online availability of 'the official version'. Many sites provide access or links to accompanying materials such as explanatory memoranda, subordinate legislation or court interpretations. Some sites offer legal rules within legislation as navigable nodes, providing links to key information including (in some cases) links to cross references and defined terms used in a legal rule. Search tools are a basic feature offered by most sites. Some sites provide solutions which enhance visualization using selection of font, font size, content and colour. A small number of sites provide point-in-time access to legislatoin. Some research sites or approaches explore the presentation of legislation or bills in radically different forms: such as graph visualizations or as topic colour-coded icons.

In this paper we first review examples of such visualizations and highlight various approaches that are available in official and public good sites in selected jurisdictions. ${ }^{1}$ We

\footnotetext{
${ }^{1}$ The visualizations selected are largely confined to the common law world, selectively reviewing sites in Australia, the United States, Canada and the United Kingdom. We have not sought to be be comprehensive in a paper of this length and we have focussed on sampling official and public good sites in jurisdictions available in English language which are most familiar to us. Undoubtedly further insights would be drawn from surveys of online visualization in other jurisdictions, including other cultural and linguistic contexts. A fuller review would also include commercial publication of legislation, which
} 
then briefly present our own visualizations that focus on the enhancement of the visualization of definitions in the parallel domain of legal contracts. Such visualizations are readily transferable to the legislative domain.

The welter of approaches available raises the question of how we may evaluate the utility of a particular visualization. On what basis are we able to suggest, for example, that a basic presentation of text is any worse than a site which provides graphical sliders allowing access to point-in-time versions of legislation? While we intuitively expect more 'advanced' visualizations to be preferable, what are our theoretical or empirical grounds for such conclusions? Furthermore we might ask, better or worse for whom? Current visualizations do not necessarily distinguish between lawyers, citizens, law makers, advocates and other users, who have quite distinct needs. Drawing particularly on the fields of information visualization and knowledge visualization, we conclude by presenting a potential theoretical framework for grounding the visualization of legislation, and discuss the evaluation of legislative visualization.

While a variety of definitions exist of what might be meant by visualization, in the context of this paper we primarily mean the use of graphics, images or symbols (other than words themselves) to enhance the communication of meaning contained in or associated with (legislative) text. While primarily in the text itself, meaning in text extends beyond the words themselves, for example information such as document structuring or relationships between concepts found in text. In Section 4 we explore this definitional issue further.

\section{A Survey of Online Visualization of Legislation}

\subsection{Before the Information Age}

Before considering the development of law online, it is worth giving some consideration to the presentation of law in its pre-online forms, as practices from this period have been carried forward in online formats. A concern to increase the accessibility of law has been long standing and continues in many respects to be unresolved. One dimension of such accessibility has been the presentation of law.

Presentation of law in earlier practice of the British Parliament consisted of great slabs of discursive text. In the early-nineteenth century, Jeremy Bentham (credited with being one of the writers influencing later reforms) vociferously critiqued the problems of legislative drafting including the failure to use such obvious tools as division of legislative texts into digestible portions and section numbering to aid retrieval. [15], [11, pp 250-251] Practices such as section numbering and the breaking up of text were officially endorsed with the passage of Britain's first Acts Interpretation Act in 1850 and bedded down after establishment in the late nineteenth century of the first parliamentary drafting office standardised a number of reforming practices in legislative presentation including the structuring of Acts in parts and the use of sub-paragraphing. (See for example Figure 2) $[11, \mathrm{p} 250],[15,22,40]$

particularly addresses the needs of lawyers and users in large organisations. 
In the early nineteenth century law was inaccessible in other senses. A measure of how far things have improved is gleaned from Bentham's observation that "the present price of the last edition of the statutes (Statutes of the Realm) exceeds the average annual income of any individual of the labouring classes in England". [11, p 239]

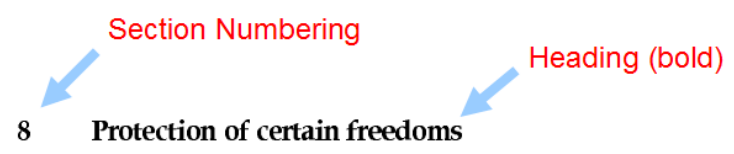

(1) The Secretary of State may not make a control order which has the effect of prohibiting or regulating any of the following activities -

(a) the communication of information in the ordinary course of scientific research;

(b) the making or is formation generally available to he public; or

(c) the communication or information that is gene ally availat.e to the public,

Sub-section and Paragraph Numbering

Figure 2: Example of now standard presentation of legislation from the UK Export Control Act 2002

law itself.
Of course we may now obtain access to the Statute book instantly and at negligible cost. The Legal Information Institute (LII) movement has made a considerable contribution to solving this problem. Despite this, legislation (or more precisely its meaning) remains in practical terms inaccessible to most citizens of modern democracies for reasons connected with the content and presentation of the

Bennion, the author of a leading text on statute law makes the following observation:

"It is strange that free societies should thus arrive at a situation where their members are governed from cradle to grave by texts they cannot comprehend." $[10, \mathrm{p} 8]^{2}$

His observation is not only poetic, it implicitly suggests a standard that legislative communication ought achieve. In 1990, the Law Reform Commission of Victoria in its report titled Access to the Law - the Structure and Format of Legislation found it pertinent to quote him. It went on to illustrate the validity of the observation by reporting on reading difficulty measures in application to legislation - demonstrating the inaccessibility of the language to all but a vanishing proportion of the population. Notwithstanding the considerable success in making legislation accessible via online means, and the achievements of the plain English movement in improving the expression of legislation, there is little to suggest that 'Bennion's Conundrum' is substantively less true today than it was in the

\footnotetext{
${ }^{2}$ Ironically, Bennion himself did not believe the problem can be fixed. He complains that he is cited as authority for reform stating 'that it is strange does not mean it is remediable'. Law, he regards as an expert domain and legislation as exclusively addressed to lawyers. The lay person, he says, ought not consider that he or she can understand it any more than the intricacies of medical knowledge without the intermediary of a medical practitioner. [9] Successive New Zealand Commissions (see below) seem to have disagreed with him (particularly the 2008 Commission). It is not an unreasonable expectation that the communications of those who govern us ought be comprehensible. The proponents of plain language convincingly demonstrate the existence of extensive empirical studies establishing the benefits of plain language to comprehension, including in the legal context and the widespread support of plain language measures to increase comprehensibility adopted by legislative drafting offices. [31]
} 
past.

In 1990 the Victorian Commission went on to identify three primary causes of legislative incomprehensibility: defective language; defective organisation; and defective layout and formatting. The second and third 'defects' overlap the field of visualization with which we are concerned. The need to trawl through multiple cross referenced sections or definitions, for example, falls within the topic of organization. Whereas facilities such as headings and numbering impact on how easily law can be found and read.

In respect of layout and formatting (the primary focus of their report) the Commission express concern about typography, density and spacing of material, the indentation of text, the placement of section and sub-section numbers in the body or margins of text and insufficient use of bold font and italics. The size of typeface is another concern. The Commission went on to advance proposals such as the greater use of graphics instead of words where appropriate (e.g. a map or flow chart). They suggested that explanatory material could be boxed and appear together with legislation. They complain that readers need to be 'warned about defined terms' (e.g. by highlighting or special marking). They also suggest the importance of indexes for legislation. They propose the use of decimal numbering systems. They address the incomprehensibility of amending legislation which cannot be read on its own, as it can only be understood if the original legislation is read together with the amending provisions. They suggest instead that the whole amended provision be shown with relevant changes being appropriately highlighted. [1]

Their 'radical' proposals did not go unmarked, though 22 years later they are still largely unadopted in the official presentation of legislation. In 1993, the Australian Commonwealth Parliament inquired into legislative drafting by the Commonwealth, canvassing among other things a number of the issues raised in the Access to the Law Report. The Committee appeared to endorse the value of use of graphics. [2, p 153] It expressed support for the use of margin layout for numbering (although calling for empirical assessment of different types of layout). [2, pp 154-155] Proposals for expressing amendments in an integrated form were met with concerns from Office of Parliamentary Counsel as to the additional material that would have to be created. Traditional book publishers supported the system then and still in use, Softlaw Corporation (known for developing the logical representation of legal rules using computational techniques) however supported reform. [2, pp 149-152] Bold font or other marking of definitions similarly received a skeptical response from Parliamentary draftsmen who expressed concern about 'distracting' the readers and legislation being more difficult to read. While attracted to the idea, the Committee wished it to be tested by proper user evaluations. [2, pp 156-157] Decimal numbering systems were rejected by the Committee on the basis of experience from the Queensland Parliament which suggested that parliamentarians found it difficult to use. [2, p 117]

Many of the proposals that seemed overly radical or impracticable in 1993 are in operation in various online sites. The bolding or marking of definitions is for example adopted in AustLII sites. CanLII, in its prototype 'point-in-time' site provides side by side mark up editing showing amendments in context, similar to contextualised amendments proposed by the Victorian Commission. The constraints of paper which earlier made formatting choices problematic are irrelevant to an online environment. 
Nonetheless in the formal legal world progress can be slow. As recently as 2008, the New Zealand Law Commission and the New Zealand Parliamentary Counsel's Office together undertook an inquiry into the Presentation of Law starting from the proposition that: 'It is a fundamental precept of any legal system that the law must be accessible to the public.' [3, p 12] It identified three factors bearing on accessibility: physical or electronic availability, users being able to know where to find the law (navigability) and that the law once found is understandable. [3, pp13-14] The second of these again bears on how law is visualized. The recommendations of this Commission were, however modest, being concerned with issues such as progressing online availability (a problem largely solved or well on the way to solution) and continuing the availability of the law in hard copy form (an anachronism in the 21st century).

\subsection{Public good publication online}

In this section we review the contribution of the LII movement to online publication of legislation.

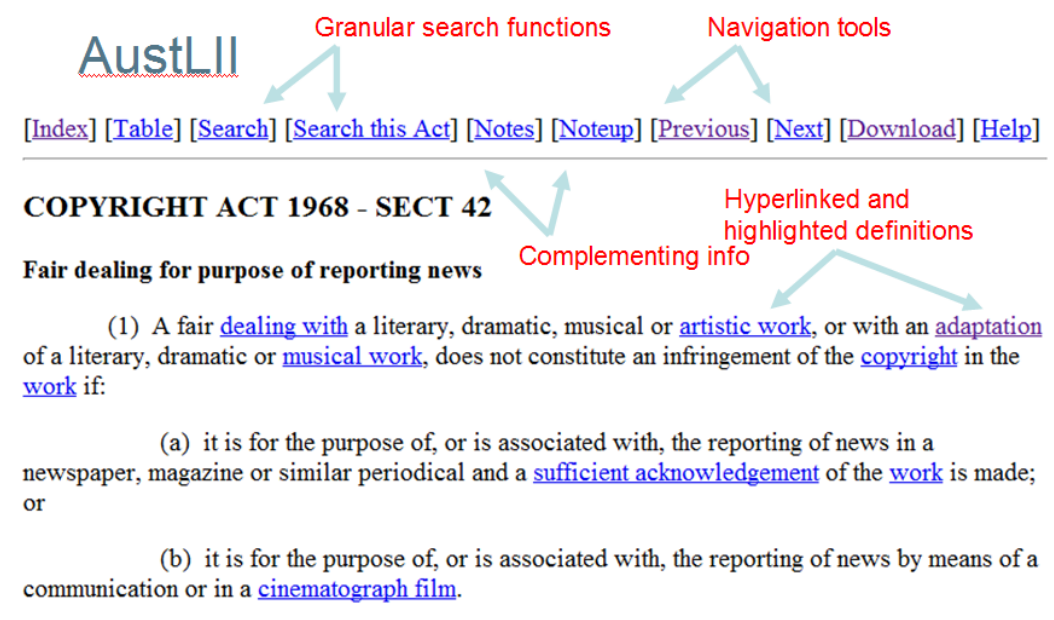

Figure 3: Visualization features provided in AustLII legislation
Peter Martin, the cofounder with Tom Bruce of the LII movement observed in 2000 that the most heavily used part of LII was its offering of the U.S. Code, automatically kept up to date by software checking government information sources. In 2000 LII was processing over a million data requests per day: a significant contribution to accessibility of law. LII's origins in 1992 were on a gopher server and the first legislation provided online was the Copyright Act. In March 1993, while snowed in by a blizzard, Martin produced a hand marked up version of the United States Constitution for the World Wide Web. These developments were virtually contemporaneous with the emergence of the World Wide Web itself. At a cost of $\$ 250,000$ per annum in its initial years, run from Cornell University Law School, LII became a major online provider of open access legal information. [37] It is an example of research driven contribution to society.

These developments were followed quickly by developments in other jurisdictions. By 1 March 1995 AustLII had established a free online site publishing, among other legal resources, Australian Commonwealth statutes and regulations. Also run out of universities (the University of New South Wales and the University of Technology Sydney), its founders, in 1995, stated their philosophy along the following lines: 
The international development of public legal information servers is part of the more general movement to create publicly available (or 'free to air') resources on the Internet, similar in some respects to the creation of public libraries in the nineteenth century. The Internet is fast becoming home to commercial providers of information, and effective means of charging for even occasional uses of resources are being developed. The countervailing movement, of which AustLII is a part, aims to ensure that some part of cyberspace is public space, where no one is denied use of resources because of financial considerations. [25]

These early LII's were followed by similar efforts in Canada and Britain (2000) and by 2005 a range of jurisdictions either had their own LII's or were in the process of establishing them. The LII movement also by 2000 had given birth to a global coalition of LII movements known as WorldLII which by 2005 provided free legal information from 55 countries. [30]

The visualization adopted by AustLII (similar to other LII sites) is in part a reflection of its time with an emphasis on hypertext functionality. While relatively uncomplicated, its features appear to be effective, and compare favourably with some of the official sites we have reviewed (some of which are nothing more than text and others which at least at level of personal preference of the authors are not as intuitive and usable). AustLII treats each section as a separate data point and provides key navigational links including: to legislative cross references in the same Act, defined terms, previous and succeeding articles, table of contents, references to materials commenting on a provision, amending notes and Act specific searchability which returns a list of individual provisions in which the search term occurs. ${ }^{3}$ (See Figure 3)

AustLII's basic features were discussed by Chung et al. in 2000 including a discussion of an assessment of AustLII against web accessibility heuristics (of interest in the context of evaluation), and a general avoidance of images (of interest in the context of visualization). Chung noted its minimalist philosophy, including the avoidance of images that do not add meaning. Perhaps this view reflected a time when images were widely and injudiciously deployed on web sites and bandwidth constraints meant adding significant time lags. [19]

As with other sites we have reviewed, the CanLII legislative site provides interesting and different features to its users. Funded by Canadian law societies, CanLII aims to provide free access to law. Originally based at the University of Montreal the development of CanLII is now carried on by Lexum, a spinout from the university. It provides a point in time comparison feature that allows the selection of any point in time version and comparison with any other version in side by side layout. Each section of legislation is also hyperlinked to a pop-up window referencing citing cases. ${ }^{4}$

\footnotetext{
${ }^{3}$ For example see AustLII, Commonwealth Consolidated Legislation, http://www.austlii.edu.au/au/legis/cth/consol_act/

${ }^{4}$ CanLII legislation site, http://www.canlii.org/en/info/legislation.html
} 


\subsection{Official sites}

Official publicly accessible sites began to emerge about the same time or shortly after the public good sites discussed above. Greenleaf notes the scaleplus offering of the Australian Attorney-General's department which was available at the time that AustLII was coming into being. [25] Martin notes that in 1995 only ten U.S. states had their legislation available online. [37] Official sites vary widely in their quality and style, although as far as we are aware no user evaluations have been carried out of any particular online framework. This review samples legislation sites in the Australia, the United Kingdom and the United States. The following selective descriptions provide a sense of where official practice lies in the online presentation of law.

\subsubsection{Selected Australian Jurisdictions}

In Australia we compare Federal with selected State and Territory sites each of which adopt different approaches.

The Commonwealth framework presents legislation in a variety of formats, with the principal presentation being through windows giving contemporaneous access to the table of contents as a clickable tree on the left of the page and window containing a html version of legislation on the right of the page. Users can select an alternative visualization providing downloadable versions in pdf, rtf or zip formats, which are represented by document icons. The official and current version of a law is indicated visually by an icon of Australia with a green tick (for example over the pdf version). The presentation is as far as possible identical for each format. The site remains close to the hard copy versions on which it is based. Each piece of legislation is provided as a whole document, rather than being disaggregated into its component sections. The site uses anchors for navigation on its html home page for each Act. An examination of the page source for the webpage indicates that considerable metadata is stored with the legislation, although this functionality is not explicit to the end user. For example a class is assigned to each block of text including classes such as definition, subsection, paragraph, section and other headings. This metadata is potentially valuable for a variety of applications. The site is maintained by the Commonwealth Office of Parliamentary Counsel, and is the only authoritative site for Australian Federal legislation. The site makes available its content on a creative commons basis and encourages linking and data mining of the text, although access is through the provided versions, rather than via an API for the underlying data. ${ }^{5}$

New South Wales maintains a site closer in form to the AustLII site with the primary presentation being a section by section navigation framework with forward and back buttons. The table of contents appears on the left and can be minimised by dragging. Search functionality is provided. The site also allows the legislation to be presented in a page of different granularity: the entire Act, a part, division or single section. Searchability for a single Act is provided. The page source shows a complex mark up. The site is

\footnotetext{
${ }^{5}$ Australian Office of Parliamentary Counsel, Commonwealth Legislation site, http://www.comlaw.gov.au/
} 
maintained by the NSW Parliamentary Counsel's Office. ${ }^{6}$

The Australian Capital Territory maintains a document oriented site providing access to the current and historical versions of legislation as separate downloadable files in pdf or rtf version. HTML versions are not provided. Great store is placed in the authenticity of the pdf version of the document which is digitally signed by the Parliamentary Counsel's Office. Icons representing the various types of document formats available are used to represent these versions on the legislation landing page. The page also provides immediate access to subordinate legislation and accompanying materials such as the explanatory memorandum. The site states its purpose to include making timely and comprehensive legislative information freely available. User friendliness is a stated goal. While a search function is provided, the search returns a whole Act or regulation, rather than a provision in which the search term occurs. (See Figure 4$)^{7}$

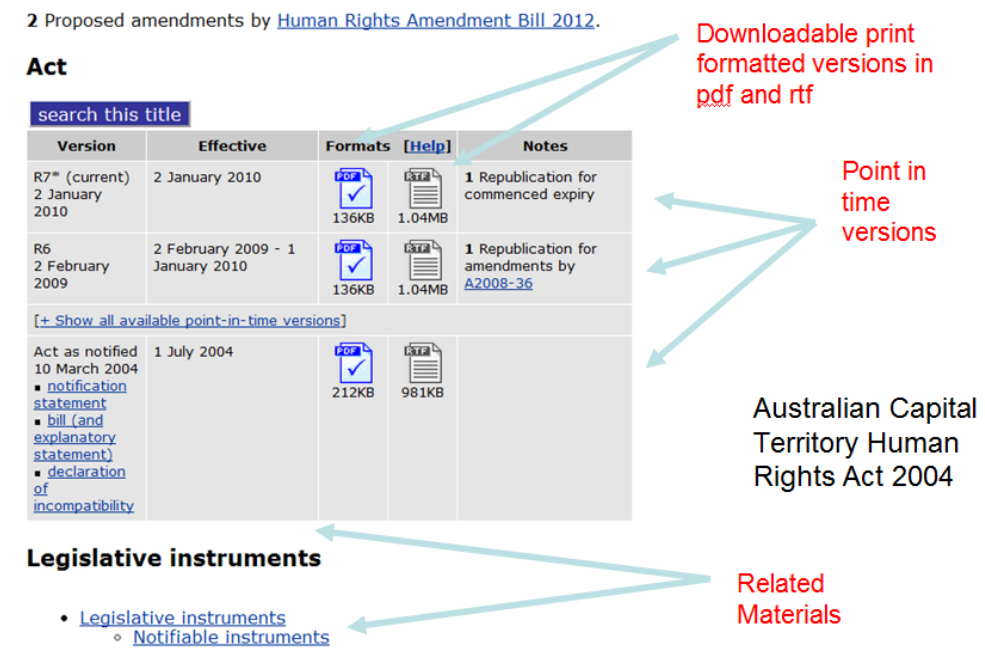

Figure 4: Document focussed visualization of ACT Human Rights Act 2004 The site provides information on how to hyperlink to specific rules in an item of legislation or the legislation as a whole. The site provides point in time access, allowing a user to view a particular rule or the entire Act at a chosen point in time. Also cross-references are activated as hyperlinks. This framework, implemented through a project called Teratext was innovative for its time, being one of the first sites to provide facilities of this kind. The project was sponsored by the Tasmanian government to improve community access to the law, taking legislation from printed (and out of date) consolidations, to online accessible law. Tasmanian law was converted to Standard Generalized Markup Language (SGML) format for this purpose and the electronic database forming the law was recognised by Act of Parliament as the official version of legislation. [6] [5]. ${ }^{8}$

\footnotetext{
${ }^{6}$ NSW Parliamentary Counsel's Office, Official NSW Legislation Site, http://www.legislation.nsw.gov.au

${ }^{7}$ ACT Parliamentary Counsel's Office, ACT Legislation Register, http://www.legislation.act.gov.au

${ }^{8}$ Tasmanian Office of Parliamentary Counsel, Tasmanian Legislation Online, http://www.legislation.tas.gov.au
} 


\subsubsection{Selected U.S. Jurisdictions}

The following paragraphs briefly review some of the government maintained sites in the United States.

The United States Code maintained by the Office of Law Revision Counsel of the United States House of Representative has recently ${ }^{9}$ been re-released in a beta site which improves its visualization. Colour is used to soften the appearance of the site. Headings are enlarged and presented in browns. The Code can be navigated at title, chapter or article level. Like other official sites, internal hyperlinks are not provided. An examination of the source code suggests presentation is generated by javax programs, presumably drawing from underlying databases. ${ }^{10}$ The current version of the US Code online at the time of writing is provided in pure ascii format downloadable as entire titles (i.e. the equivalent of a scroll). (See Figure 5) The site warns readers that the online version of the Code is not official and to refer to the printed version for the 'official' text. Access is provided in pdf format to chronological statutes as issued by the Congress. The older site provides a search function. ${ }^{11}$ The beta site is a considerable advance in technology and visualization.

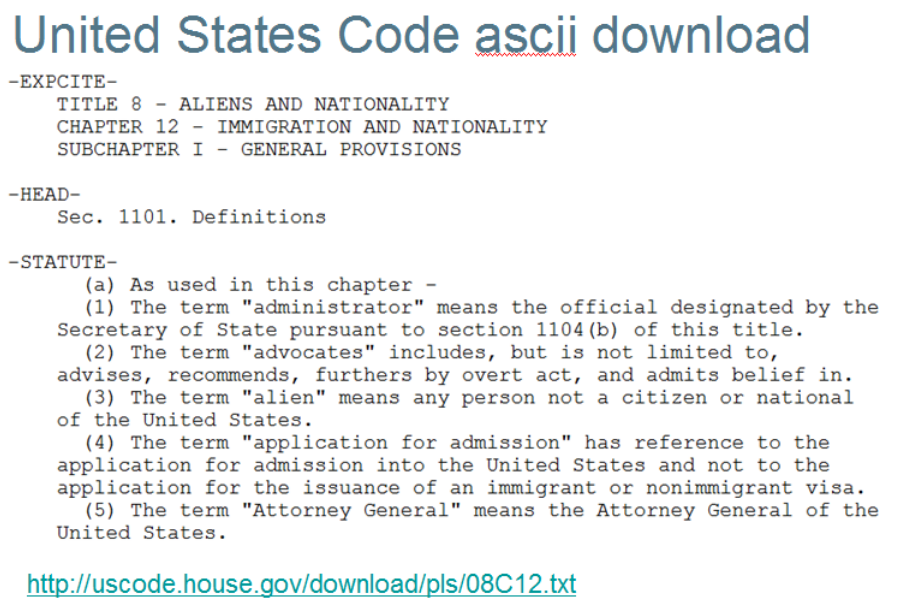

Figure 5: Simple ASCII presentation of download of US code

Virginia is another jurisdiction currently undergoing reform of its online presentation of law. A site provides the kind of features seen in the US Code case: use of colour and bold font to enhance readability. Navigation is provided through the availability of previous and next buttons to navigate from section to section. Rare for an official site, the beta site provides internal crossreference hyperlinks allowing a reader to immediately navigate to a referenced article or to an amending Statute. The table of contents and a search feature are also available on every page. It is not possible to call law at different levels of granularity (e.g. an entire title or chapter). The underlying technology is an '.exe' program which is called by html href tags, presumably interfacing with an underlying database. ${ }^{12}$ An examination of the 'classic site' suggests that much of what is described above was already available in the older site, with enhance-

\footnotetext{
${ }^{9}$ As of July 2012

${ }^{10}$ Office of Law Revision Counsel of the US House of Representatives, United States Code Beta Site, http://uscodebeta.house.gov/

${ }^{11}$ Office of Law Revision Counsel of the US House of Representatives, United States Code site, http://uscode.house.gov/

${ }^{12}$ Division of Legislative Automated Systems the Virginia General Assembly, Code of Virginia, http://lis.virginia.gov/000/src.htm
} 
ments largely focussed on adjusting the visual presentation. At article level presentation remains unchanged, except in regard of change of font to increase readability.

Oregon's government provided online site is limited to the 2011 edition of the Oregon Revised Statutes. Readers must themselves refer to the statutes adopted in 2012 to determine the current state of the statute book. Instructions are provided to readers on how to do so. Whole of text searchability is provided for the site but little else. To access the law, the user navigates to the individual chapter of the law which is presented to the reader in its entirety. Examination of the underlying source page indicates that the underlying data is nothing more than a word document that has been converted to html format. This online version is explicitly stated not to constitute the official Oregon Revised Statutes, which are only available in hard copy form by the Oregon Office of Legislative Counsel. ${ }^{13}$

\subsubsection{The United Kingdom}

The United Kingdom's online legislative site is maintained by the UK National Archives and provides access through tables of contents and section level access. Laws can be viewed in html format or downloaded in pdf format. Entire Acts, parts of Acts or single sections can be viewed. At section level forward and back buttons provide ready sequential navigation of provisions. Point in time access is available through a clickable timeline which the user can display.

Geographical application of the law is also visualized through an inline icon which indicates which of the jurisdictions of England, Wales, Scotland and Northern Ireland the legislation applies to. An interesting innovation is the preparedness to use very prominent footnoting and marking to signal changes to the text or relevant commentary. (See Figure 6.)

Examination of source

\section{UK Human Rights Act}

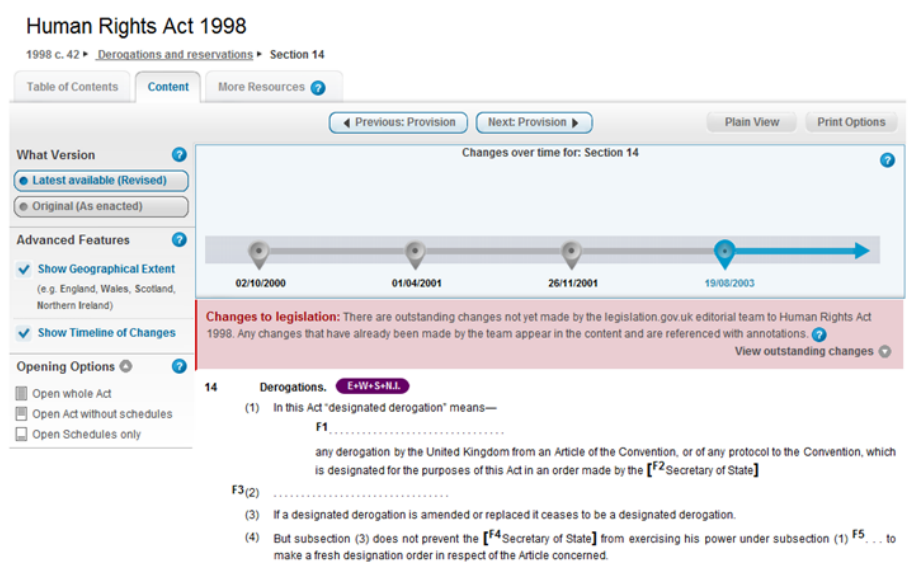

Figure 6: Point in time and edit annotations in UK Human Rights Act visualization pages indicates that underlying data is maintained in an xml schema and css and javascript are used extensively. Information is made freely available under an open government licence (including scripts and data). ${ }^{14}$ Unusually (perhaps uniquely for an official site) the UK, through

\footnotetext{
${ }^{13}$ Legislative Counsel Committee of the Oregon Legislative Assembly, Oregon Revised Statutes, http://www.leg.state.or.us/ors/

${ }^{14}$ UK National Archives, the Official Home of the Revised Enacted United Kingdom Statutes,
} 
the Office of Public Sector Information, also provides a legislation API (Application Programming Interface), enabling developers to directly access and republish (or otherwise use) the underlying legislative data. The API pages emphasise that the development of the legislative data base began with an API. It appears to be one of only two official re-conceptualisations of legislation as data rather than law. ${ }^{15}$

\subsection{Legislative Data and Hacker Visualizations of Law}

The work described above has largely been carried out in the context of major institutions, whether primarily universities (in the case of the LII movement), or government agencies in the case of officially maintained sites. The availability of law as data is however a profound change that gives rise to the possibility of groups even as small as one or two people making their own visualizations or analyses of legislative data available. We see some examples of these new possibilities below.

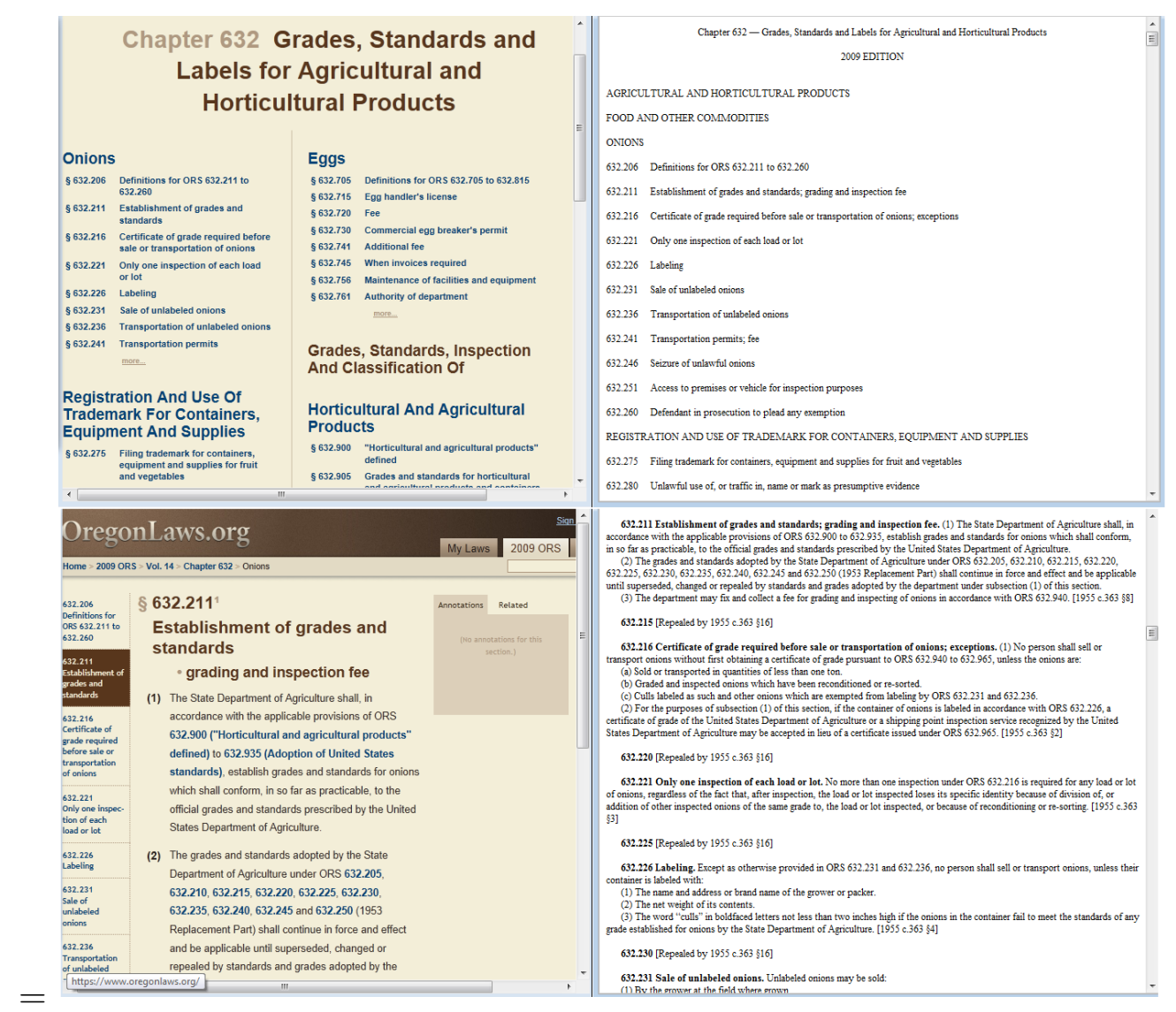

Figure 7: Comparison of Presentations of Oregon legislation

Oregon Laws which appears to be maintained by a single individual does not radically reshape the presentation of laws, but does use simple tools to significantly enhance their

http://www.legislation.gov.uk/

${ }^{15}$ Office of Public Sector Information of the UK National Archives, Legislation API Developer Site, http://www.opsi.gov.uk/legislation-api/developer/. The second (and earlier) site is that established by the Tasmanian government, which as early as 1996 provided in section 5 of the Act that the Office of Parliamentary Counsel must maintain a database of legislation, and in section 6 that the databased constituted the official version of the law. 
presentation. In contrast to the public site, which as we have seen presents the law as 'unofficial' plain text in lengthy chapter by chapter blocks, Oregon Laws provides hierarchical navigation to the section level and uses simple techniques such as heading sizes, colour, bold font and 'more' tags to achieve a visually informative and aesthetic presentation of laws. Frames are used to provide information on related statutory provisions (extracted via citation analysis) and the broader context of a section is contextualised by a block style menu list. Referenced provisions used in an article are hyperlinked and highlighted. ${ }^{16}$ (See Figure 7.)

The Virginia Code for Humans site is another small scale 'hacker' visualization of law supported by grants from philanthropic foundations. (See Figure 8.)

It enhances the presentation of legislation by use of features such as colour and font size. It also provides 'cloud' navigation of topics in the legislation and hyperlinking of definitions (a feature also provided on the official beta site). The site provides pop-up visualization of the defining text of defined terms where it is used in a legal rule. This is an obvious enhancement that might

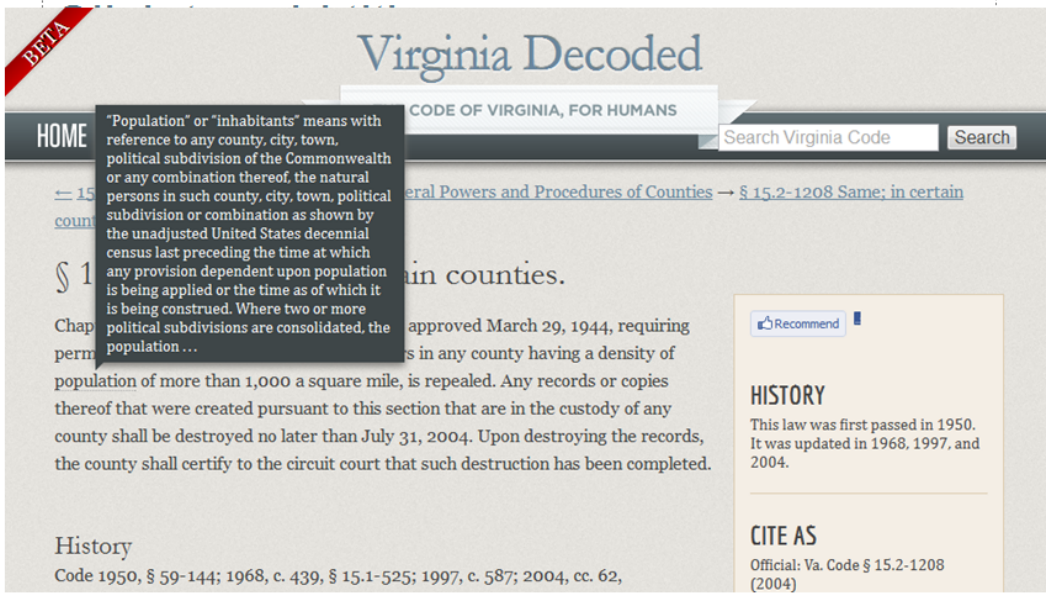

Figure 8: Waldo Jaquith's Virginia Decoded with definition text popup be made to the visualization of law (but does not seem to have been used anywhere apart from this site). ${ }^{17}$ The site adopts an explicitly 'open access' philosophy, releasing both underlying data and making the underlying source code for the visualizations developed in php and mysql are released as open source under a GPL licence. ${ }^{18}$

The developer, Waldo Jaquith explicitly states his purpose to be the enhancement of the presentation of legislation 'to make it all more understandable to normal humans'.

State codes are wretched. Seriously, look at a few: California's, New York's, Illinois', and Texas' are all good examples of how stunningly difficult that it is to understand state laws. They don't have APIs. Virtually none have bulk downloads. You're stuck with their crude offerings. ${ }^{19}$

Jaquith's views are hard to argue with. Though there are some developments towards improving government provided online legislative sites, we have seen in our brief survey that they may consist of nothing more sophisticated than an online text dump, with a

\footnotetext{
${ }^{16} 2011$ Oregon Revised Statutes, https://www.oregonlaws.org/oregon_revised_statutes

${ }^{17}$ Waldo Jaquith, Virginia Decoded - The Code of Virginia for Humans, http://vacode.org

${ }^{18}$ see also Waldo Jaquith, The State Decoded Source Code Repository, https://github.com/waldoj/statedecoded

${ }^{19}$ Waldo Jaquith, the State Decoded About page, http://www.statedecoded.com/about/
} 
linking table of contents and may not even constitute the official version of the law.

\subsection{Novel and Purpose Specific Visualizations}

So far we have examined sites which have largely been motivated by the primary purpose of making laws available. Even for this single purpose, the diversity of approaches is significant. The following visualizations illustrate the potential for legislative data to be visualized in novel ways for a variety of purposes, including direct expression of the meaning of a legal rule.

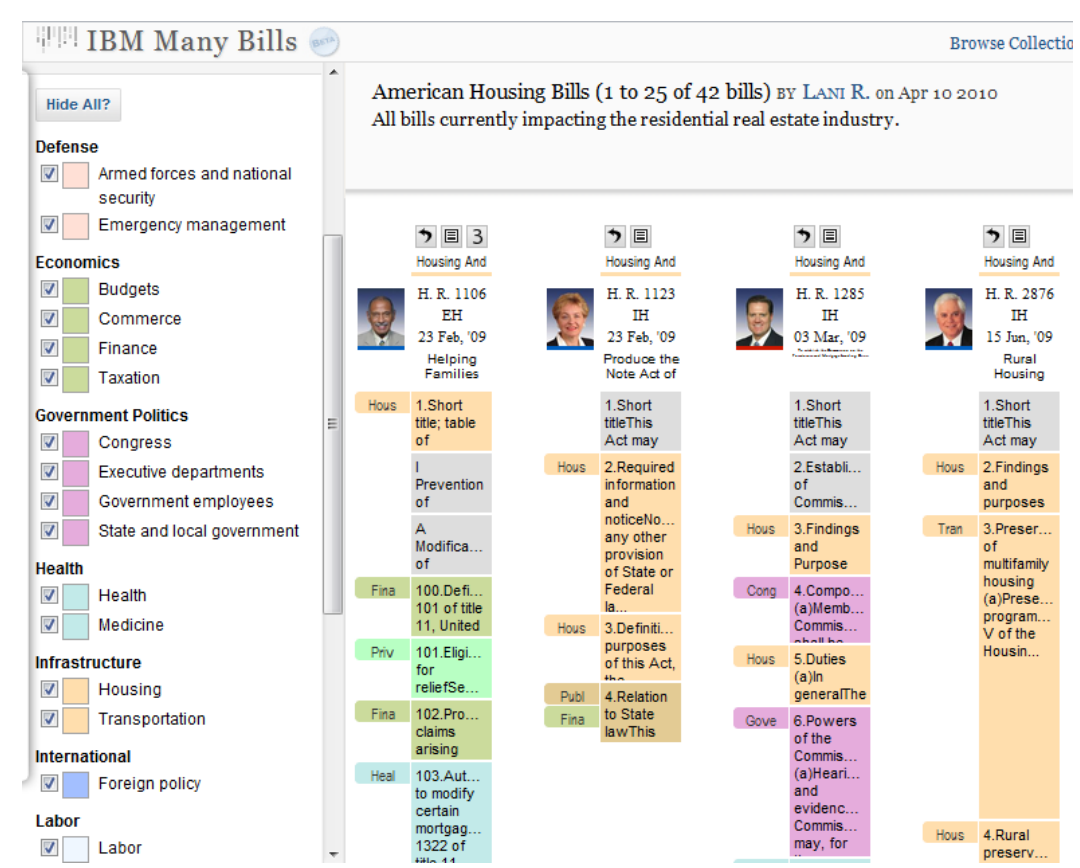

Figure 9: IBM ManyBills Topic Icon Visualization
Word clouds are rarely used in formal legislative sites. Such clouds can however be readily found on the internet and employed for the casual review of specific laws. ${ }^{20}$. Critics of the Northern Territory intervention in Australia, which was purported to be for the purpose of addressing child abuse in indigenous populations, point out that the words 'child' and 'children' do not appear in the legislation at all and instead that words related to land and its control appear frequently in the

Northern Territory Emergency Response Act. They use a word cloud to illustrate their point. ${ }^{21}$ Matt Stiles at the Texas Tribune uses a word cloud to assess the legislative priorities of legislators, finding most Bills are concerned with community issues such as education. ${ }^{22}$ IBM researchers present a word cloud of the most frequently used words in EU legislation titles. ${ }^{23}$ These presentations seek to make sense of complex legislative data for political or descriptive purposes. The Virginia Code for Humans on the other hand makes traditional use of a word cloud - i.e. a hyperlinked summary of key concepts explored by an item of legislation.

\footnotetext{
${ }^{20}$ By searching for 'legislation' and 'word cloud'

${ }^{21}$ Jens Korff, Creative Spirits, Northern Territory Emergency Response, http://www.creativespirits.info/aboriginalculture/politics/northern-territory-intervention.html

${ }^{22}$ Matt Stiles, the Texas Tribune, 6 January 2011, Word Cloud Shows Lege Priorities So Far, http://www.texastribune.org/texas-legislature/texas-legislature/word-cloud-shows-lege-prioritiesso-far/

${ }^{23}$ IBM Research and IBM Cognos Software Group, Visualizations: Words Used in Titles of EU Legislation 2011, http://www-958.ibm.com/software/data/cognos/manyeyes/visualizations/words-used-in-thetitles-of-eu-leg
} 
ManyBills seeks to address the 'length', 'complexity' and 'obscurity' of bills, providing an interactive environment in which bills and their topic are presented in colour coded 'blocks' which enable the user to distinguish topic areas covered by bills. These topics may be disparate as a result of the political process. The system also provides information on congressional sponsors of bills. It deploys visualization and data mining techniques to extract and present topic related information. Users are able to view Bills at a document and section level. This visualization provides access to law by focussing on graphical presentation and use of colour rather than text to convey information. [7] (See Figure 9.)

(2) If the driver is to leave the roundabout less than halfway around it, the driver must enter the roundabout-

(a) from the left marked lane; or

(b) if the road is not a multi-lane road-as near as practicable to the left side of the road. Example-

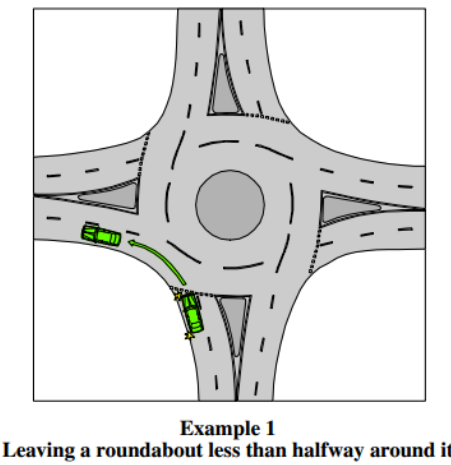

Figure 11: What lane to use turning left on a roundabout

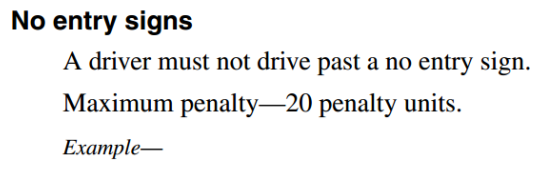

Figure 10: Explaining a no entry sign

Bommarito and Katz' work on the United States Code, rather than being concerned with visualization for end user purposes seeks to visualize the United States Code for the purposes of research insight. They particularly seek to assess the complexity of law and the evolution of that complexity over time. They represent the Code as dual overlaid hierarchical and citation networks, exploring a number of properties of these networks, and particularly examining the issue of complexity. [13] [14]

Rasmussen is a small scale commercial venture which describes itself as 'opening up political data, structuring, analyzing and visualization it'. ${ }^{24}$ Among its visualization is a flash animation of the development of fields of EU legislation, using growing bubbles to represent the growth of the number of laws adopted in such fields. The purpose of such a visualization is to illustrate their respective importance and growth over time. ${ }^{25}$ Rasmussen also take the trouble to provide an API for European Union legislation which interfaces with official EU legislative sources. They describe their API as helping 'you conduct research, create data visualizations or you can even build applications upon it'. ${ }^{26}$

It will be noted by the reader that none of the visualizations examined so far seek to directly present the meaning of legal rules in graphical form.

The work of Haapio and Passera is a demonstration of the potential for visualization to

\footnotetext{
${ }^{24}$ Buhl \& Rasmussen, Data Analysis, http://www.buhlrasmussen.eu/index.en.html

${ }^{25}$ Buhl \& Rasmussen, the Evolution of European Legislation, http://epdb.eu/eulegislation/

${ }^{26}$ Buhl \& Rasmussen, API for European Union Legislation, http://api.epdb.eu/
} 
play an integral role in the expression of legal rules. Combining legal and graphic design skills they illustrate the clarity that is obtained by using graphical features such as a timeline to represent when the contract is in effect and possible termination events, the use of transportation icons to represent passage of risk and ownership of goods in transit and the use of bar charts to convey the relationship between delay and liquidated damages. $[27,28,38]$ Their work is outside the computational context but conceivably computational tools could be created to facilitate the drafting of 'visual rules', or automated translation from text to visual representation, in appropriate cases.

In Australia a legislative case which uses graphics to directly communicate the meaning of legal rules are the Queensland Transport Operations (Road Use Management-Road Rules) Regulation 2009 which are liberally illustrated with explanatory diagrams to enhance the communication of meaning. (See Figures 10 and 11.)

\section{Visualizing Definition Networks}

In this section we briefly outline work undertaken to develop prototypes for the representations of definitions and their associated networks within the context of contracts, which are a parallel domain for legislation. This work will be fully reported in a separate article which has been submitted for publication. ${ }^{27}$ It is part of broader research exploring the development of software based tools for enhancing the reading and writing of law. Visualization is a subsidiary portion of the scope of envisaged work, but nonetheless an important one. Previous papers have explored the characterisation of legal language in contracts, through profiling of a corpus of contract documents, [21] and the use of rule based methods, machine learning and hybrid techniques for the automatic classification of text in contracts. [20]

There are of course many potential visualization enhancements that might be addressed. In a contractual context starting with definitions reflects the significant proportion they form of contracts and their role in controlling contract meaning. ${ }^{28}$ They also of course play an important role in legislation and directly impinge on the readability and expression of law. Definitions are typically defined in a glossary or definitions section and are then used throughout a legal document. Many sites do not provide any special enhancements to assist in the use of definitions. Some sites provide hyperlinks allowing immediate navigation to a defined term from a legal rule where it is used. The only site however which we are aware of which provides in context pop-up access to the meaning of a defined term is the Virginia Code for Humans developed by Waldo Jaquith, which we discuss above.

We have developed a number of prototype visualizations of definitions and their associated networks that may be of assistance to readers or drafters of contracts or legislation. We describe them briefly. ${ }^{29}$

\footnotetext{
${ }^{27}$ Michael Curtotti, Eric McCreath, Srinivas Sridharan Software Tools for the Visualization of Definition Networks in Legal Contracts - under peer review.

${ }^{28}$ One of the author's experience in the negotiation of contracts as an in-house lawyer was the genesis of the identification of definition networks as an area where visualization may be useful.

${ }^{29}$ These visualizations can be viewed at http://buttle.anu.edu.au/contracts/
} 
A. Definition Network Graph Visualization: Definition networks sometimes form networks where one definition will refer to another in how it is defined. Such graphs can be complex (even in contracts). This visualization provides a node and link diagram which expresses such connectivity between defined terms. This kind of visualization is potentially useful to readers in seeing the relationships between defined terms used in a legal document. In contrast to the multi-layer pop-up (described below) it provides an immediate single view access to an entire definition network.

B. Single and Multi-Layer Pop-up Defined Term Navigation: As we saw above the Virginia Code for Humans is the only site of which we are aware that uses pop-ups to allow the meaning of a defined term to be accessed in context. We provide similar functionality, but also provide a prototype visualization allowing direct multilayer navigation through a definition network from the rule where the defined terms are used. This is potentially of particular use to readers who often have to navigate a complex network of referenced material before the meaning of a rule can be understood. After navigating three or four pages away from the rule (either through hyperlinks or by scrolling through a text document) the reader is seeking to comprehend, comprehension can be considerably reduced.

C. Definition Clouds: Use of word clouds in respect of legislation is rare as we have noted above. There is however considerable scholarship evaluating the utility and effectiveness of word clouds. $[8,29,36]$ Features such as placement, font, colour and size of text of varying effectiveness. We develop a 'definition cloud': which although using the same basic arrangements, is conceptually distinct in that it leverages from an existing human created ontology within a legal document. We use size to indicate frequency of usage and traffic light colour scheme to indicate how much of the meaning of a definition is hidden in defined terms used in the definition. A comparison with a more traditional word cloud is provided.

D. Usage and Obfuscation Icons: An alternative representation of the same information is provided by a small circular icon placed on the left of each definition. A pie chart in this case indicates how much of the text is 'hidden'. A number placed over the icon provides a usage metric, indicating importance of the provision. This and the previous visualization are potentially useful to drafters in reducing the complexity of their drafts and to readers in identifying defined terms that require particular attention.

E. Definition-Rule Network Matrix Visualization: This visualization draws on a tool used in social network analysis and provides a summary representation of the relationship between defined terms and the rules in which they are used. These relationships can signal semantic and topic connectivity between potentially separate parts of a legal document. Weight of relationship is indicated by the darkness of each matrix square.

Such visualizations are largely novel in application to legal documents but their development has been guided by experience in working with legal documents and are for that reason appealing (at least to their creators). This is by no means a sufficient basis for expressions of confidence in their value and below we discuss the topic of evaluation of visualizations, and one of our goals is to carry out such evaluation in future research. Future work will also include extension of such tools to a demonstration legislation site. 


\section{Towards a Theory of Legislative Visualization?}

As evident from the review above, practice in the visualization of legislation is diverse. There does not seem to be a theoretical framework grounding such visualization. Indeed, there does not appear to be a shared consensus, or even a developing discourse, on what 'good practice guidelines' might look like. Is it really the case, for example, that the dumping of ascii text online in a bulk presentation of law is not as good a visualization as a presentation which presents formatted individual rules? The absence of such theoretical frameworks means that is difficult to pursue the systematic enhancement of online visualization of legislation: standards and approaches appear arbitrary as they are not non-verified. For these reasons a theory or at least empirical results as to a body of 'good practice' is required to enhance visualization.

\subsection{Visualization Theory}

The absence of a theoretical framework for the visualization of legislation is related to the broader problem in information visualization as a whole. Researchers in the information visualization field describe the absence of theory, or agreed theory. As information visualization ranges over disparate fields the problems are compounded by the diversity of disciplinary constructs that might be applied. Is information visualization to be approached as a problem of cognitive science taking into account the way the brain processes visual information? [4], [43] Or as a problem in information theory emphasising the transmission and encoding of information? [18] Perhaps decision science, which asks how individuals make decisions, applying concepts of utility, should be applied to design questions? [45] Further we have choices such as approaching the problem as one of 'science' with a focus on discovering the principles of information visualization or one of 'engineering' with a focus on application of principles to the creation of software artefacts. [24]

Underlying such questions are even more basic questions of what we mean by visualization. Particularly what do we mean by visualization in the context of legislative documents? We may note that text (consistent with its origins in speech) is a sequence of symbols (words) used to convey meaning. It is essentially one dimensional and meaning is conveyed to the reader as symbols are sequentially parsed. Although a reader 'sees' the text, the processes by which the reader absorbs information from text are adapted from the how we process speech. Visualization, by contrast, is grounded in sight rather than hearing/speech. Ordering may be important or irrelevent in the visualization context. A visualization may be one, two, three or four dimensional (if changing over time). How we extract meaning from what we see, is significantly different from how we extract meaning from text.

In this broad but general context, definitions associated with the concept of visualization are better understood. Burkhard defines knowledge visualization in the following terms:

Knowledge visualization examines the use of visual representations to improve the transfer of knowledge between at least two persons or group of persons. [16] 
Legler and Eppler suggest the following definition for a 'visualization method':

A visualization method is a systematic, rule-based, external, permanent, and graphic representation that depicts information in a way that is conducive to acquiring insights, developing an elaborate understanding, or communicating experiences. [34]

Information visualization is defined as the computer assisted use of visual processing to gain understanding. $[16,17,34]$

Tegarden notes that visualization 'allows decision-makers to use their natural spatial/visual abilities' and that it 'exploits the human visual system to extract information from data'. [44]

For the purposes of this paper, drawing on ideas such as these by 'visualization' we intend the use of graphics, images or symbols (other than the words themselves) to enhance the communication of meaning contained in or associated with (legislative) text.

\subsection{Suggestions for Framing Legislative Visualization}

Given the diversity of approaches potentially available it is reasonable to focus on those ideas that intuition suggests may be particularly useful or relevant to the task of visualization legislation. Of course this statement carries assumptions - it is an applied approach - prioritizing specified task oriented outcomes over a general theoretical framework. For our purposes (enhancing the visualization of legislation) this makes sense. Grinstein presents a conjecture for addressing visualization problem of this kind. [26]

Given a data set D, given a task $T$, for a given display, there exists a visualization $V$ such that the perceived information $I$ is such that task $T$ is optimally perceptually/cognitively "resolved". This means that no other visualization will solve task $T$ as well or that the perceived information $I$ is the best for resolving task $T$.

While such mathematical formalism will not necessarily appeal to all tastes, it is a useful crystallisation of the issues that need to be addressed in developing a visualization and helps us clearly express our intended meaning. As Grinstein notes a number of terms are undefined or unknown or measures to be defined.

While generally useful for the visualization of legislation we can adapt it to be more precisely targetted for our needs:

Given a set of legislation $L$, given a user $U$ with task $T$ requiring knowledge of $L$, there exists a visualization $V_{1}$ with features $F_{1}$ to $F_{n}$ such that the perceived knowledge $K_{p}$ conveyed to $U$ for task $T$ is better perceptually/cognitively "resolved" than in a given set of visualizations $V_{2}$ to $V_{n}$.

If our interest is the performance of a particular task or achieving a particular outcome, such as increasing a user's access to law, then such a framework suggests how we might practically and systematically pursue such a desired outcome to enhance visualization 
outcomes. It draws us to questions such as the following: Who are our intended users? What are their needs and relevant characteristics? What tasks would they intend to carry out. What visualization features are to be provided? For enhancing the communication of what knowledge? How effective are they such communication as compared with existing visualizations?

The inclusion of the user $U$ in the framework allows us to distinguish between different users of legislation - such as drafters, parliamentarians, legal and professional advisers, activists, researchers or members of the public, whose tasks $\mathrm{T}$, will differ and will be conditioned by their intended outcomes, pre-existing knowledge and needs. We see, for example, that the visualizations produced by Bommarito and Katz, who were seeking to visualize the complexity of an entire body of legislation, address an entirely different task to that which might face a legal adviser who may for example be seeking to predict legal outcomes against given facts.

Confining the problem to comparison of a set of given visualizations enables us to undertake empirical evaluation against existing legislative visualizations (such as those surveyed above) as opposed to developing a theoretically 'optimal' model. How such optimality might be discovered in the abstract is not necessarily evident.

The substitution of a knowledge parameter for the information parameter, emphasizes a 'knowledge visualization' framework which again is more suited to our needs. Although Grinstein notes that the end point in information visualization is 'does the user get it?', and the two concepts are closely related, generally information visualization is focussed on the extraction of new insights from data, whereas the explicit purpose of knowledge visualizations as conceptualised by Burkhard is to improve the transfer of knowledge between individuals or groups. [16] This focus is again congruent with the legislative context, where for example government may be seeking to make knowledge available to the citizen, either to ensure the citizen knows their rights, or complies with the law.

The inclusion of features $(\mathrm{F})$ in our model again enables us to focus on those elements that contribute to performance for a given task. For example point-in-time access may be particularly valuable to a lawyer seeking to litigate a case based on events that occurred some years ago, it may be less pertinent to a member of the public seeking to know the current state of the law.

\subsection{Evaluating Legislative Visualizations}

Having such a framework we may also observe that there is a universal baseline against which any online visualization of the law may be tested - i.e. the hard copy version of the legislation. At a minimum we would wish task $\mathrm{T}$ to be better resolved in an online visualization than for a user using the paper text of a law.

Of course central to such a model are empirical studies of visualizations, which are widely agreed to be essential to progressing information visualization in a coherent fashion. $[24,26,35,39,45]$

The need for empirical evaluation is not a new insight. As we have seen, the Australian 
Parliamentary Committee charged with reviewing the drafting of legislation in 1993 realized that user evaluations were critical. They considered that human testing would be preferable to any automated testing against metrics, and urged that testing be given priority. They, in particular, rejected readability metrics as of assistance in this context, noting that such measures correlated poorly to real world issues with readability of legislative provisions. In evidence presented to the Committee, the Commonwealth Office of Parliamentary Counsel stated that they planned to undertake a program of testing of a limited number of statutes for the purposes of comparing plain language and then current drafting styles. [2, pp 98-103] Krongold discusses the importance of testing whether individuals are able to understand legislation, preferably during drafting. Like other observers, Krongold is critical of the value of tests such as the Fleisch scale or FOG index, noting that such measures are neither adequate or accurate for legislative documents. She particularly notes that although a negative score may be accurate, a positive score using such indexes has little relationship with actual readability. She notes further that the metrics were developed for general prose and were never tested on legislation. [32, pp $544-545]$

Reported evaluations of presentational or visualization aspects of legislative text are very rare. A study of this kind is reported by Stewart who is particularly concerned with section headings in legislation and undertakes usability testing to test two propositions: that the redrafting of section headings as questions would assist in comprehension, and that the addition of headings for subsections would assist in comprehension. Metrics used in undertaking the tests included time on task and accuracy of responses. [42] Another study which combines presentational improvements with plain language enhancement of the Canadian Employment Insurance Act finds clear usability benefits from the combination of such features. Graphical features included use of colour, bold font, font sizing and careful font choice and underlining of defined terms. [12,23] Passera notes that the combination of plain language enhancements with these visualization changes means that it is not possible to determine the specific contribution made by visualization enhancements as they were not measured separately. Passera's own evaluation of the effect on usability of visualizations in the parallel domain of contract visualization establishes the usability improvements associated with use of diagrams and charts, improving typography and layout out, highlighting key terms, utilizing color-coding in a redesigned table of contents. She tests and confirms four hypotheses: that visualizations support faster reading and more accurate understanding, provide a more positive experience than text only contracts and affect user expectations positively. [38]

A notable officially undertaken evaluation of visualization together with plain language features was a 2010 survey commissioned by the Australian Commonwealth Office of Parliamentary Counsel (OPC) as to user evaluations of enhancements to presentational features of Australian law. The First Parliamentary Counsel notes that 'during the 1990 's, OPC experimented with a range of innovations to our drafting style'. The evaluation is limited to professional user groups (judges, tribunal members and their associates, lawyers, Commonwealth employees involved in instructing or advising on law and parliamentary officers). ${ }^{30}$ The selection of 'users' is significant and reminds us of Bennion's words as to the audience for whom laws are (implicitly or explicitly) written. Ideally

\footnotetext{
${ }^{30}$ First Parliamentary Counsel Letter Survey of Users of Legislation 14 December 2010 http://www.opc.gov.au/plain/pdf/2010LegislationSurveyLetter.pdf
} 
(given the communication and open access considerations discussed above) such surveys would include members of the public with varying experience of use of legislative materials. An indication that a broader survey would provide additional insights is indicated by the divergence in response between members of the legal fraternity as opposed to Commonwealth employees (the latter more positive on average than the legal group in respect of all innovations). The essentially 'offline' conception of the evaluation is notable. None of the questions asked as part of the survey, mentioned or addressed issues specific to the online provision of law (e.g. users experience of using the online site), despite the transition to the online environment being the most significant delveopment of the period under review.

Nonetheless the survey stands out as one of the few official systematic evaluations and validation of selected innovative visualization (and other) elements in legislation. The survey enabled the OPC to validate certain innovations providing evidence for continuing and extending their use and called into question others, against the needs of a selected user group. Features such as the new format for legislation; the new form of commencement provisions; the use of notes; the use of tagging of concepts; the use of tables; and the use of subsection headings rated well. The survey also provided an opportunity for OPC to seek the opinion of users as to other potential enhancements that could be made. Among innovations suggested for consideration which are relevant to this paper were: use of hyperlinks for online versions of laws and 'an online layout compatible with word' (e.g. the need for ready reproducibility in legal advice). Also private sector legislation users mentioned that "what they needed was clear and plain legislation ... legislation had become overly complex'. Interestingly the user group did not respond positively to 'diagrams', the use of which accordingly is to be reduced. [41] Passera's results are perhaps an indication that the needs of business users may differ from those professionally immersed in the use of legal texts.

In the information visualization field, there are well developed methodologies for evaluation with a variety of approaches available. Plaisant et al discuss a number of them including controlled experiments comparing design elements, usability evaluation of a given tool to refine its design, controlled comparative evaluations of two or more tools (a common type of study) and case studies of tools in realistic scenarios. [39] These kinds of studies are common to research methods in human computer interaction which include also methodologies such as diaries (as a tool for evaluating user experience), focus groups and interviews, automated collection of data, and ethnographic studies. [33] Such literature describes the well established and widely utilised methodologies available for evaluation and we have proposed above one possible framework against which evaluation of online legislative visualizations might be carried out, although undoubtedly others can be imagined.

The apparent dearth of evaluations of the online visualization of law is curious. One reason for the limited number of such studies may be unsurprising - cost and difficulty - a factor noted in the Commonwealth Parliamentary inquiry. Another may be the lack of coherent theoretical frameworks described above. It may however simply be a function of the cultural patterns which develop (or not) within a particular community of practice. However given the well established practice of evaluation within the field of human computer interaction, and a similarly well established tradition of evaluation that the plain language movement brought to the offline improvement of legislative texts, [31] 
greater attention is warranted as to how evaluation might be systematized as standard practice in online publication of legislation.

\section{Conclusions}

This paper has selectively reviewed online visualization of legislation in the context of pursuit of open access to the law. This has highlighted the diversity of practice in the field and the absence of measures or standards for determinging the quality of online legislative visualization. The review also indicated that some official sites lag behind the state of the art (although the state of the art itself is unevaluated). The Law Via the Internet movement remains among the most prolific providers of online legislation through its LII sites, despite the gradual progress evident in work to enhance official sites. Some sites provide examples of the potential for easy enhancements that might be adopted by other sites or for radical new visualizations of law to improve access for existing users, address new user needs or enable new questions to be addressed. The essentially arbitrary nature of the various approaches illustrated and the wide range in quality enables us to conclude that there exists significant scope to enhance the online visualization of legislation.

Of particular interest is the emergence of the first official legislative data repositories and associated API's which are conceived as such. This may prove in the long run to be among the more significant developments of recent years, as it provides the potential for legislation to be accessed or analyzed in ways only limited by human imagination. Sites such as Oregon Laws and the Virginia Code for Humans, illustrate that even small groups of actors with limited resources can provide original and enhanced visualizations once the data itself is accessible. Considerations such as these suggest that it would be useful for official providers of legislation to be encouraged to provide and maintain access to legislative data sets together with API's to assist developers (and researchers) to access that data for a wide variety of purposes.

We report prototype visualizations of definition networks in the parallel domain of contracts and discuss the potential for these visualizations to provide useful tools for users of legal documents. The visualization should only be taken as an example of one dimension in which legislative visualization is open to enhancement. Assessing the merits of such visualizations and empirically identifying the range of potential enhancements that better meet user needs can only be reliably determined on the basis sound theory and empirical evaluation as we have argued in this paper.

The exploration of a potential theoretical framework and the evaluation of visualizations addresses the need to systematise approaches and learning that could be drawn from the current diversity of online legislative visualizations. Without a systematic approach to determining what is 'good' visualization, development will likely be haphazard and progressive enhancement will proceed more slowly than might otherwise be the case. Developing a coherent body of knowledge in respect of visualization of legislation and its evaluation may contribute significantly to further advancing accessibility for users of online legislative sites.

There has been remarkable progress in the last 20 years in furthering accessibility to law 
and the contrast with past exclusion of the general population from the law could not be greater. Making law available online for free is an astonishing achievement by the people who have brought it into being. The work of the plain language movement has also been a significant feature of the last years. Yet Bennion's Conundrum remains: 'we find ourselves in the profoundly undemocratic situation that we are governed from cradle to grave by laws that most of us cannot comprehend'. The platforms established in the last twenty years, apart from their direct benefits, offer a departure point for addressing (or further addressing) other dimensions that impede accessibility to law (such as how law is expressed, how it is organised, how it is visualized). It is clear that there are many other possibilities that might be explored, including tools to transform what has largely been a static and formalised process of unidirectional communication of law from government to the governed, into an ongoing conversation between law makers and law users (and among law users themselves) as to the legal rules under which we live. It would not be difficult, for example, for tools to be provided to allow legal rules to be rated by online users, or for comment facilities to provide direct and immediate feedback to those who write the law, and valuable information for parliamentarians.

In future work we intend extending our current work on contracts to legislation and undertaking evaluation of the benefits or otherwise of proposed enhancements or tools, such as tools for visualization of definition networks.

\section{References}

[1] Access to the Law - the structure and format of legislation. Technical Report 33, Law Reform Commission of Victoria, 1990.

[2] Clearer Commonwealth Law: Report of the Inquiry into Legislative Drafting by the Commonwealth. Technical report, House of Representatives Standing Committee on Legal and Constitutional Affairs, 1993.

[3] Presentation of New Zealand Statute Law. Technical Report 104, New Zealand Law Reform Commission and New Zealand Parliamentary Counsel's Office, 2008.

[4] E. Anderson, C. Scheidegger, and C. Silva. The Role of Perception and Cognition Costs in Models of Visualization Effectiveness. VizWeek 2010: The Role of Theory in Information Visualization, 2010.

[5] T. Arnold-Moore. Point in time publication for legislation (xml and legislation). In Proceedings ot the 6th Conference on Computerisation of Law via the Internet, Paris, France (December 2004), 2004.

[6] T. Arnold-Moore, J. Clemes, and M. Tadd. Connected to the law: Tasmanian legislation using enact. Journal of Information Law and Technology, 1, 2000.

[7] Y. Assogba, I. Ros, J. DiMicco, and M. McKeon. Many bills: engaging citizens through visualizations of congressional legislation. In Proceedings of the 2011 annual conference on Human factors in computing systems, pages 433-442. ACM, 2011. 
[8] S. Bateman, C. Gutwin, and M. Nacenta. Seeing things in the clouds: the effect of visual features on tag cloud selections. In Proceedings of the nineteenth ACM conference on Hypertext and hypermedia, pages 193-202. ACM, 2008.

[9] F. Bennion. If it's not broke don't fix it: A review of the new zealand law commission's proposals on the format of legislation. Statute L. Rev., 15:164, 1994.

[10] F.A.R. Bennion. Statute law. Oyez, 1983.

[11] J. Bentham. Nomography, or the art of inditing laws. The Works of Jeremy Bentham (ed. J. Bowring), 3:231 et seq, 1843.

[12] D. Berman. Toward a New Format for Canadian Legislation: Using Graphic Design Principles and Methods to Improve Public Access to Law. http://www.davidberman.com/NewFormatForCanadianLegislation.pdf, 2000.

[13] M. J. Bommarito and D.M. Katz. Properties of the United States Code Citation Network. Arxiv preprint arXiv:0911.1751, 2009.

[14] M. J. Bommarito and D.M. Katz. A mathematical approach to the study of the united states code. Physica A: Statistical Mechanics and its Applications, 389(19):4195-4200, 2010.

[15] F. Bowers. Victorian reforms in legislative drafting. Tijdschrift voor Rechtsgeschiedenis, 48:329, 1980 .

[16] R.A. Burkhard. Learning from architects: the difference between knowledge visualization and information visualization. In Information Visualisation, 2004. IV 2004. Proceedings. Eighth International Conference on, pages 519-524. IEEE, 2004.

[17] S.K. Card and J. Mackinlay. The structure of the information visualization design space. In Information Visualization, 199\%. Proceedings., IEEE Symposium on, pages 92-99. IEEE, 1997.

[18] M. Chen and H. Jaenicke. An information-theoretic framework for visualization. $V i$ sualization and Computer Graphics, IEEE Transactions on, 16(6):1206-1215, 2010.

[19] P. Chung et al. A defence of plain html for law: Austlii's approach to standards', 2000 (1). The Journal of Information, Law and Technology (JILT), pages 00-1.

[20] M. Curtotti and E. McCreath. Corpus Based Classification of Text in Australian Contracts. In Proceedings of the Australasian Language Technology Association Workshop 2010, 2010.

[21] M. Curtotti and E. McCreath. A corpus of australian contract language. In Proceedings of the Thirteenth International Conference on Artificial Intelligence and the Law 2011, 2011.

[22] M. Evans and R.I. Jack. Sources of English Legal and Constitutional History. Butterworths, 1984.

[23] GLPi and V. Smolenka. A Report on the Results of Usability Testing Re- 
search on Plain Language Draft Sections of the Employment Insurance Act. http://www. davidberman.com/wp-content/uploads/glpi-english.pdf, 1964.

[24] L. Grammel and M.A. Storey. Towards a foundation for information visualization engineering. VizWeek 2010: The Role of Theory in Information Visualization, 2010.

[25] G. Greenleaf, A. Mowbray, and G. King. Public legal information via internet: Austlii's fist six months. Austl. L. Libr., 3:144, 1995.

[26] G. Grinstein. Arguments for a theory of visualization. VizWeek 2010: The Role of Theory in Information Visualization, 2010.

[27] H. Haapio. Contract clarity through visualization-preliminary observations and experiments. In Information Visualisation (IV), 2011 15th International Conference on, pages 337-342. IEEE, 2011.

[28] H. Haapio and S. Passera. Reducing contract complexity through visualization-a multi-level challenge. In Information Visualisation (IV), 2012 16th International Conference on, pages 370-375. IEEE, 2012.

[29] M.J. Halvey and M.T. Keane. An assessment of tag presentation techniques. In Proceedings of the 16th international conference on World Wide Web, pages 13131314. ACM, 2007.

[30] Miller J. The development of the legal information institutes around the world. Can. L. Libr. Rev., 30:8, 2005.

[31] J. Kimble. Answering the critics of plain language. Scribes J. Leg. Writing, 5:51, 1994.

[32] S. Krongold. Writing laws: Making them easier to understand. Ottawa L. Rev., 24:495, 1992.

[33] J. Lazar, J.H. Feng, and H. Hochheiser. Research methods in human-computer interaction. John Wiley \& Sons Inc, 2009.

[34] R. Lengler and M.J. Eppler. Towards a periodic table of visualization methods for management. In IASTED Proceedings of the Conference on Graphics and Visualization in Engineering (GVE 2007), Clearwater, Florida, USA, 2007.

[35] Z. Liu and J. Stasko. Theories in information visualization: What, why and how. VizWeek 2010: The Role of Theory in Information Visualization, 2010.

[36] S. Lohmann, J. Ziegler, and L. Tetzlaff. Comparison of tag cloud layouts: Task-related performance and visual exploration. Human-Computer InteractionINTERACT 2009, pages 392-404, 2009.

[37] P.W. Martin. The mushrooming virtual law library on the net. In Cornell Law Forum, volume 27.

[38] S. Passera. Enhancing contract usability and user experience through visualizationan experimental evaluation. In Information Visualisation (IV), 2012 16th Interna- 
tional Conference on, pages 376-382. IEEE, 2012.

[39] C. Plaisant. The challenge of information visualization evaluation. In Proceedings of the working conference on Advanced visual interfaces, pages 109-116. ACM, 2004.

[40] D Renton. The preparation of legislation - report of a committee appointed by the lord president of council, 1975.

[41] Orima Research. Office of Parliementary Counsel results of 2010 legislation users survey.

[42] G. Stewart. Legislative drafting and the marginal note. Statute Law Review, 16:21, 1995.

[43] O. Swienty and M. Takatsuka. From subjectivity to objectivity in information visualization: challenges in bridging the gap between cognitive theory and information design. VizWeek 2010: The Role of Theory in Information Visualization, 2010.

[44] D.P. Tegarden. Business information visualization. Communications of the AIS, 1(1es):4, 1999.

[45] J.S. Yi. Toward practical information visualization theory: Lessons from the history of decision science. VizWeek 2010: The Role of Theory in Information Visualization, 2010. 